\title{
Desenvolvimento de Museu Virtual Utilizando Ferramentas Livres
}

\author{
José R. Merlin *, Mateus A. Simon ${ }^{\dagger}$, Matheus M. Bertonha ${ }^{\ddagger}$, Daniela F. G. Trindade ${ }^{\S}$ e Wellington D. Mura ${ }^{\natural}$ \\ Universidade Estadual do Norte do Paraná \\ Rodovia BR 369 - KM 54 - Bandeirantes - PR \\ *merlin@uenp.edu.br \\ †mateus@uenp.edu.br \\ †bertonha2011@gmail.com \\ §anielaf@uenp.edu.br \\ ฯwellington@uenp.edu.br
}

\begin{abstract}
Resumo-Com o advento da word wide web a partir dos anos 1990, muito do que existia apenas no mundo "físico" começou a existir também no mundo "virtual". Um exemplo são os museus que, embora tradicionalmente sejam lembrados como instituições de preservação de objetos históricos ou obras de arte, também guardam outros tipos de coleções. Neste trabalho é abordado o museu entomológico, que consiste em uma coleção de insetos organizada principalmente para fins de estudo. $O$ objetivo foi analisar a viabilidade da utilização exclusiva de software livre no desenvolvimento de um museu entomológico virtual. Desta forma, esta categoria de software foi utilizada, desde a aquisição e tratamento das imagens até a disponibilização do resultado final na web. $O$ método mostrouse viável e de baixo custo, evidenciando que as ferramentas utilizadas são totalmente eficazes no que se propõem.
\end{abstract}

Palavras-chave - museu virtual; software livre; entomologia.

\section{INTRODUÇÃO}

A utilização de software livre no desenvolvimento de produtos apresenta a vantagem, dentre outras, de diminuir o custo. Neste artigo é apresentada uma abordagem para desenvolvimento de museu virtual com tecnologias livres. Um museu virtual pode ser desenvolvido em um tempo menor, se comparado com os museus "de tijolos", e é independente de localização geográfica, o que facilita a visitação [1]. Os museus virtuais surgem no contexto da era da informação, ou era digital, iniciada com o surgimento da web a partir dos anos 1990. Isto, de acordo com [2], trouxe consequências no que diz respeito a forma como os museus se organizam e se apresentam.

Neste artigo é relatado o desenvolvimento de um museu entomológico virtual, chamado Entomuseu, construído com o objetivo de analisar a viabilidade da utilização do software livre nesta tarefa. Constatou-se que é possível utilizar apenas esta categoria de software na construção de museus virtuais.

Nas seções seguintes são apresentadas uma breve fundamentação teórica sobre museus virtuais, as ferramentas de software livre utilizadas para o desenvolvimento do Entomuseu, as etapas de desenvolvimento, os resultados alcançados e, por último, a conclusão.

\section{Museus e Museus EntomolóGicos}

Embora o termo "museu" lembre coleções de interesse histórico, também pode ser utilizado em outros contextos. Para o ICOM - International Council of Museums [5], o conceito de museu é definido como:

[...] uma instituição permanente que não possui fins lucrativos a serviço da sociedade e seu desenvolvimento, aberto ao público, que adquire, conserva, pesquisa, comunica e exibe o patrimônio tangível e intangível da humanidade e do meio ambiente para fins de educaçaõ, estudo e prazer.

De acordo com [12]:

[...] museu é um espaço institucional permanente, a serviço da sociedade e que tem um caráter educacional não formal, caracterizado pelo conhecimento descentralizado, simbólico e participativo, de motivação pessoal, que prima pela preservação, valorização e divulgação de todo e qualquer acervo que abriga em suas dependências.

Com o advento da web, surgiram os museus virtuais, que nas palavras de [8] podem ser definidos como:

[...] uma coleção logicamente relacionada de objetos digitais compostos de variados suportes que, em função de sua capacidade de proporcionar conectividade e vários pontos de acesso, possibilita-lhe transcender métodos tradicionais de comunicar e interagir com visitantes [...] não há lugar ou espaço físico, seus objetos e as informações relacionadas podem ser disseminados em todo o mundo.

Segundo [7] embora o papel do museu continue vital, as formas com que as tarefas de coletar, preservar, estudar e exibir os conteúdos, precisam mudar e se adaptar a era digital. Para o autor, ocorrem mudanças nas seguintes tarefas:

- Preservação: os museus se deparam com um desafio para conservar suas coleções no mundo digital, uma vez que para executar esta tarefa eles dependem de data centers, empresas e especialistas externos. 
- Obtenção: hoje o museu virtual, além de criar o objeto digital em si, precisa criar um metadados sobre os objetos, pois o metadados são a chave para entender a coleção digital.

- Exploração: as coleções digitalizadas expostas na rede mundial abrem incontáveis possibilidades de pesquisas. Para aproveitar as vantagens de tais oportunidades os museus precisam de duas condições básicas: eles precisam digitalizar suas coleções e tornar um inventário disponível online. Isto requer a padronização de metadados de tal forma que os registros possam ser efetivamente utilizados. Já estão surgindo padrões para definição de metadados para museus.

- Exibição: as coleções físicas continuarão a serem expostas da forma que já estão, no entanto nas digitais é necessário criar adaptações, como por exemplo, para os dispositivos computacionais em geral, como computadores pessoais, smartphones e tablets.

Conforme mencionado anteriormente, o termo "museu" pode se referir a diversos tipos de coleções. O museu abordado neste trabalho é o museu entomológico, entendido como uma coleção de insetos devidamente classificados, que facilite o estudo de entomologia.

Entomologia é uma área da zoologia que estudo os insetos, sendo responsável pela análise das características físicas, comportamentais e reprodutivas desse grupo de animais, assim como também sua relação com outros seres [3]. A entomologia é fundamental para áreas como agricultura e saúde, entre outras.

Existem vários museus entomológicos virtuais, tais como o Museu de Entomologia da USP [21], Strickland Entomological Museum [22] e Museo Entomólogico Francisco Luis Gallego [23].

\section{A. Museu de Entomologia USP}

O Museu de Entomologia da Universidade de São Paulo (USP) foi criado em 2004, com uma coleção de insetos que foi iniciada em 1965 no Departamento de Entomologia da Universidade [21]. Atualmente conta com aproximadamente 8.000 espécies e a possibilidade de navegação em duas línguas (Inglês e Português). O motivo do projeto foi a disponibilização pública na web de uma coleção dos insetos de laboratório com fotografias das espécies, facilitando a identificação.

O site possibilita apenas a visualização das espécies por meio das fotografias. Ele não conta com nenhuma descrição da espécie, do gênero ou da família. Pode-se observar que o museu se limita a apresentar fotografias das espécies existentes no museu físico. Um exemplo de visualização é mostrado na Figura 1.

\section{B. Strickland Entomological Museum}

O Museu Virtual de Entomologia do Departamento de Ciências Biológicas da University of Alberta (Strickland
Figura 1. Exemplo de apresentação da espécie

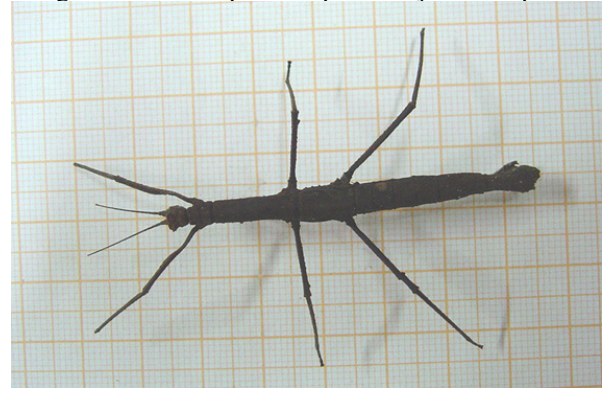

Fonte: ESALQ [21].

Entomological Museum), foi criado em 2001 com o objetivo de fornecer o acesso eletrônico da coleção da universidade, considerada uma das mais importantes do Canadá, contendo aproximadamente um milhão de espécies [22].

$\mathrm{O}$ site fornece duas maneiras de encontrar as espécies no banco de dados, a primeira é a busca individual, para a qual deve ser informada a ordem da espécie e o nome científico. No segundo tipo de busca, são apresentadas as ordens cadastradas na base de dados em sequência alfabética, contendo um menu com a lista das características das famílias existentes. Ao acessar uma delas, são carregadas as espécies.

As espécies são apresentadas por meio de fotografias 2D, acompanhadas de uma linha com a medida em centímetros do inseto. Um exemplo é apresentado na Figura 2.

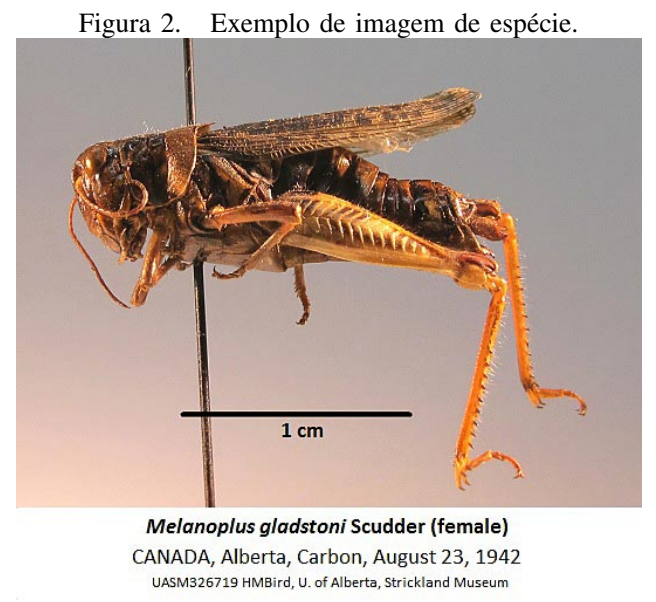

Fonte: Strickland Entomological Museum [22].

\section{Museo Entomólogico Francisco Luis Gallego}

O Museu entomológico Francisco Luis Gallego, da Universidad Nacional de Colômbia, contém fotografias das espécies existentes no museu físico [23].

$\mathrm{O}$ site apresenta em sua página inicial 13 ordens mais conhecidas dos insetos e posteriormente cada família pertencente. Diferente dos outros, neste não é possível escolher a espécie para ser apresentada. Nele é carregado uma única 
imagem com maior resolução contendo todas as espécies existentes na coleção, que pertencem a família escolhida, como no exemplo mostrado na Figura 3. Pode-se observar que a foto é retirada por cima dos insetos, os quais são fixados em um painel e que as espécies são todas da mesma família.

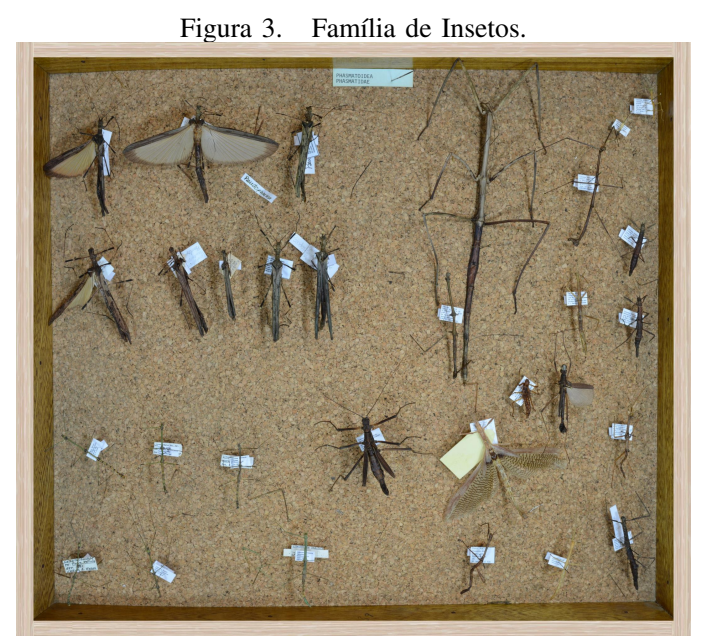

Fonte: Museo Entomólogico Francisco Luis Gallego [23].

A partir da análise dos três museus apresentados, o museu foco da presente pesquisa foi projetado, com o objetivo de oferecer uma visão mais rica ao usuário. Ao contrário dos outros museus mencionados, no Entomuseu o usuário pode manipular a imagem, observando certos detalhes que não poderiam ser notados em uma imagem 2D. Para este propósito, somente ferramentas livres foram utilizadas, as quais são mostradas na próxima seção.

\section{Ferramentas Livres Utilizadas}

O uso de software livre apresenta diversos benefícios ao projeto, tais como gratuidade, confiabilidade, possibilidade de personalização, além de melhorias rápidas e constantes. São alternativas viáveis aos softwares proprietários, embora estes ocasionalmente possam ser mais conhecidos [19].

Para o desenvolvimento do museu entomológico aqui apresentado, foram utilizados dois grupos de software. O primeiro grupo é composto pelas ferramentas necessárias a apresentação do museu na Internet, denominadas aqui como Ferramentas para Web. Já o segundo grupo engloba os softwares necessários ao tratamento das imagens ou Ferramentas para Multimídia.

\section{A. Ferramentas para Web}

A criação de sistemas para a Internet requer o conhecimento de uma gama de tecnologias responsáveis pela apresentação das informações, formatação, manipulação de dados, processamento de regras de negócio, etc. Além disso, ainda são necessários conhecimentos sólidos sobre os protocolos de transporte de dados, segurança e técnicas para garantir o desempenho do sistema. Essa situação remete ao uso de diversas tecnologias como HTML, CSS e Javascript para criar a interface com o usuário além do uso de um servidor de páginas capaz de oferecer conteúdo dinâmico processado em tempo de execução, utilizando linguagens de programação como Java, PHP ou Python [20].

Para a construção do projeto proposto foram escolhidas tecnologias baseadas em software livre capazes de fornecer confiabilidade e agilidade no desenvolvimento e uma base robusta capaz de garantir uma boa escalabilidade. Devido a esses requisitos, foi escolhida a linguagem Java, o servidor de páginas Tomcat e sua especificação padrão JavaServer Faces. Para a persistência de dados foi necessário o uso de um Sistema Gerenciador de Banco de Dados (SGBD), optandose pelo uso do PostgreSQL por motivos de confiabilidade e robustez.

O framework JavaServer Faces (JSF) é uma tecnologia Java para o desenvolvimento de aplicações web [4]. Esta ferramenta permite a criação organizada e rápida de interfaces de usuário com uma comunicação simples com o servidor de aplicações e suas regras de negócio. Uma das diversas vantagens é abstrair o uso de tecnologias como HTML, CSS e Javascript, gerando o código necessário mesmo com pouco conhecimento dessas tecnologias. O JSF é composto por três partes:

- Um conjunto de componentes de interface gráfica préfabricados;

- Um modelo de programação dirigido a eventos; e

- Um modelo de componente que permite a utilização de componentes adicionais desenvolvidos por terceiros.

Além disso, com o JSF o programador pode se dedicar à lógica sem se preocupar com detalhes de requisições e respostas das chamadas ao servidor. Em complemento ao JSF, utilizou-se uma biblioteca de componentes desenvolvida por terceiros, mas também um software livre denominada Primefaces.

O Primefaces é uma biblioteca de componentes que permite o desenvolvimento de "aplicações ricas para internet" (Rich Internet Applications - RIA), como são chamadas as aplicações que executam em um navegador web [15]. Os componentes Primefaces são componentes visuais que fornecem suporte a AJAX de forma nativa. AJAX é um método de atualização de páginas que possibilita que uma parte da tela seja atualizada sem a necessidade de recarregar toda ela, otimizando assim a apresentação das informações, oferecendo uma melhor experiência ao usuário.

Para servir as páginas escritas com JSF e Primefaces, foi necessário o uso de um servidor de aplicações. A especificação Java EE prevê diversas implementações de containers capazes de atuar como servidores de aplicações. Um servlet container é um ambiente onde os servlets (classes Java que tratam requisições recebidas de clientes web) são executados Neste projeto foi utilizado Tomcat como container devido à sua popularidade e confiabilidade. 
No presente trabalho, PostgreSQL foi utilizado como SGBD para o gerenciamento de administradores e insetos. Os administradores precisam de autenticação para atualizar a base de insetos. Este é um software de código aberto que possui versão para todos os sistemas operacionais e conta com uma comunidade de desenvolvimento muito ativa ${ }^{1}$.

\section{B. Ferramentas para Multimídia}

Uma das principais características no projeto desenvolvido foi a exibição dos objetos do museu por meio de modelos 3D. Para que essa funcionalidade pudesse ser alcançada, foram necessários o processamento das imagens e o uso de ferramentas Javascript capazes de oferecer a visualização diretamente no navegador.

Para o processamento inicial das imagens e sua preparação foi utilizada a biblioteca FFmpeg e seus utilitários de linha de comando. A biblioteca FFmpeg é compatível com Windows, macOS e Linux, e é capaz da conversão de arquivos em diversos formatos. Segundo [16], FFmpeg é uma coleção de softwares livres e bibliotecas de código aberto. $\mathrm{O}$ nome do projeto originou-se do grupo de padrões de vídeo MPEG, acrescido de "FF", que é a sigla de fast forward (avanço rápido) . A funcionalidade utilizada neste trabalho foi a conversão de vídeos em imagens.

A partir dessas imagens convertidas e tratadas apropriadamente, foi utilizada a biblioteca Javascript jQuery Interactive $3 D$ para criar modelos interativos. A linguagem Javascript, juntamente com HTML e CSS, é uma das três principais tecnologias da web, pois permite criar páginas interativas. A importância inicial de JS foi permitir que scripts fossem executados do lado do cliente e interagissem com o usuário sem a necessidade de processamento no lado do servidor. Atualmente, a linguagem evoluiu e é também utilizada no lado servidor para inúmeras aplicações [17]. A biblioteca jQuery Interactive $3 D$ [18] permite a criação de objetos interativos 3D com a utilização de diversas imagens como frames. Por meio deste script o usuário pode girar a imagem e observá-la em diversos ângulos. Uma das utilizações deste plugin é exibir produtos de catálogos de lojas virtuais.

jQuery Interactive $3 D$ é um script reponsável por criar um objeto 3D por meio de um número definido de imagens $^{2}$. Neste script existe um arquivo HTML e um código JavaScript responsáveis por unir imagens e apresentar a visualização com a possibilidade de rotacioná-las em um ângulo de 360 graus. No exemplo mostrado na Figura 4 pode-se notar que, com poucas linhas de código, é possível "unir" várias imagens para que, quando o usuário a estiver manipulando, tenha a impressão de que é um objeto 3D.

\section{ETAPAS Do DESEnVOlVimento}

O objetivo deste trabalho foi desenvolver um museu virtual que exibe imagens de insetos as quais possam ser

\footnotetext{
${ }^{1}$ www.postgresql.org/about

${ }^{2}$ www.jqueryscript.net
}

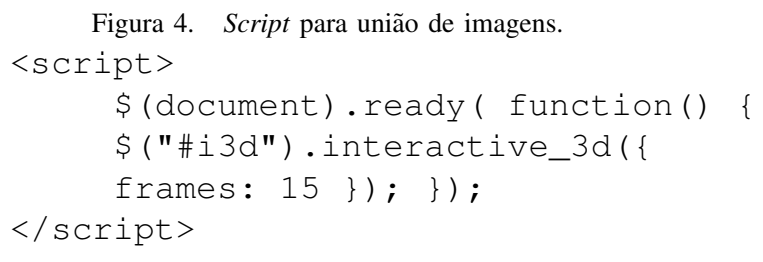

Fonte: os autores.

manipuladas pelo usuário. Para tanto, as imagens precisaram ser capturadas e tratadas para serem incorporadas à página web de exibição.

\section{A. Obtenção das imagens}

Inicialmente, foi elaborado um filme de cada inseto, em que ele é girado completamente. Este filme foi transformado em imagens, com a utilização da ferramenta FFmepg. Após diversos testes, com mais e com menos frames, chegou-se à conclusão de que um conjunto de 15 imagens são necessárias para um bom resultado final. A utilização de 15 frames facilita o carregamento delas, ao mesmo tempo que não ocasiona perda de qualidade. A realização da filmagem da espécie para posterior transformação em fotografias necessitou da construção de um artefato que girasse o inseto para que ele pudesse ser filmado. Este dispositivo, apresentado na Figura 5, foi elaborado com placas de isopor, um motor de impressora (sucata), agulha de anestesia e uma bateria 9 volts para alimentação de energia. A agulha foi presa no motor, cuja velocidade é controlada por meio de dimmer, e o inseto preso a ela. Uma câmera filma o giro de 360 graus do inseto, filme este que posteriormente será "quebrado" em fotografias. Cada filme dura cerca de 4 segundos. O processo é descrito por [9].

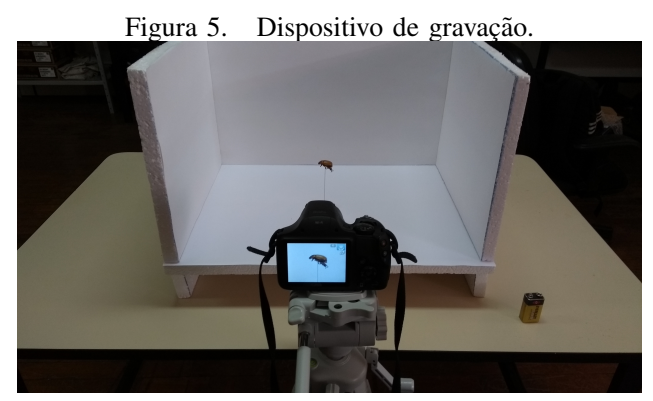

Fonte: os autores.

Para cada inseto foi realizada mais de uma filmagem, possibilitando posteriormente selecionar a melhor delas para ser transformada em fotos.

\section{B. Tratamento das imagens}

Uma vez realizada a gravação, o próximo passo foi obter os frames dos vídeos. Isso foi possível por meio da utilização do FFmpeg, convertendo os vídeos em imagens. O comando utilizado é mostrado na Figura 6, em que: 
ffmpeg .exe: nome do programa

-ss 00:00:00: momento a partir do qual as imagens começam a ser geradas

-t 00:00:03: tempo de captura após o início, durante o qual as imagens serão obtidas

- i origem.mp 4: arquivo de origem (vídeo)

-qscale:v 2: qualidade das imagens geradas, cuja escala varia entre 2 e 31 , sendo 31 a de pior qualidade

-r 5.0: quantidade de frames por segundo que devem ser capturadas

-frames 15: quantidade máximo de frames que devem ser gerados

frame_ood.png: nome dos arquivos de saída (imagens)

Figura 6. Comando para conversão de vídeo em imagem.

ffmpeg.exe -ss 00:00:00 -t 00:00:03

-i origem.mp4 -qscale:v 2 -r 5.0

-frames 15 frame_od.png

Fonte: os autores.

Após a obtenção das imagens, o próximo passo é transferilas para o museu entomológico virtual, descrito a seguir.

\section{Transferência das imagens}

Com todas as imagens prontas, elas devem se transferidas para o diretório do jQuery Interactive $3 D$, o qual permite visualizar as 15 imagens como um objeto 3D.

Para exportar as imagens, no servidor foi criado um diretório que serve como um modelo para elaboração dos arquivos de configuração de cada espécie, apresentado na Figura 7. No diretório denominado modelo existem duas pastas. A primeira (index) contém um arquivo criado em HTML o qual é responsável por distinguir o tipo de visualização que o usuário deseja (horizontal ou vertical) e redirecionálo corretamente para tal visualização. Já a segunda pasta (jquery) contém os arquivos do Interactive $3 D$.

Figura 7. Diretório modelo.

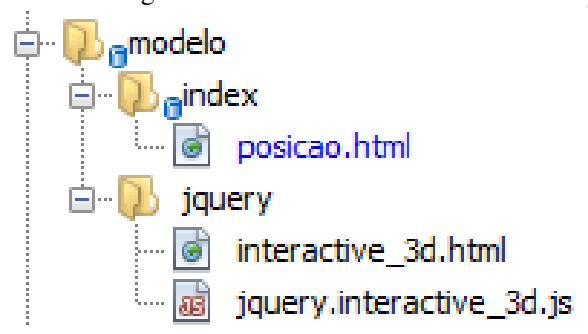

Fonte: os autores.

A necessidade de se criar uma pasta para visualização horizontal e outra para vertical se deve ao fato de que foram realizadas duas filmagens, uma com o corpo do inseto na vertical e outra com o corpo na horizontal.
Quando o servidor recebe um upload das imagens, primeiramente ele prepara o diretório no qual persistirá as imagens e os arquivos de configuração, isto é realizado para cada novo inseto cadastrado. Este diretório é criado seguindo cinco passos, descritos a seguir:

1) Inicialmente é criada uma pasta cujo nome é o ID do inseto que está sendo cadastrado;

2) Para dentro dessa pasta é copiado do diretório modelo o arquivo "index.html";

3) Ainda dentro dela, cria-se mais duas pastas, a "horizontal" e a "vertical";

4) Dentro de cada uma são copiados os dois arquivos contidos dentro da pasta "jquery" do diretório modelo;

5) Finalmente são gravadas as imagens do upload dentro da pasta correspondente a seu tipo de visualização, com todos os arquivos de configuração criados e configurados.

Estes passos foram automatizados por meio de código Java na aplicação. Assim, quando o administrador faz o upload de um novo inseto, todas as pastas e arquivos são criados automaticamente.

\section{Visualização}

Uma vez que as imagens e os scripts estejam corretamente posicionados em suas respectivas pastas, as imagens dos insetos estão prontas para serem visualizadas pelo público.

Para consultar a imagem de um inseto, primeiramente o usuário seleciona a ordem desejada, a família, o gênero e, por fim, a espécie que será apresentada para visualização em 360 graus.

A tela de consulta é mostrada na Figura 8.

Após a escolha da espécie abre-se uma tela na qual o usuário escolhe o tipo de visualização desejada, se vertical ou horizontal, pois ambas são disponibilizadas.

$\mathrm{Na}$ Figura 9 são apresentados três momentos de observação de um inseto. É importante ressaltar que o usuário pode girar o inseto com o mouse, movimento este impossível de representar em um documento impresso.

\section{E. Módulo do administrador}

$\mathrm{O}$ administrador conta com duas funcionalidades no sistema: gerenciar usuários e gerenciar insetos. $\mathrm{O}$ gerenciamento de usuários consiste em manter os administradores do sistema, que podem alterar a base com os insetos cadastrados. A consulta é pública, não necessitando que o usuário seja cadastrado.

Para inserir um inseto no sistema, o administrador deve informar a ordem, a família e o gênero da nova espécie, bem como o nome e uma descrição do inseto. A tela de cadastro é apresentada na Figura 10. Estas informações são exibidas durante a consulta.

Logo após cadastrar as informações, o usuário administrador obrigatoriamente deve enviar as fotos para pelo menos um ângulo de visualização, seja ele vertical ou horizontal. 
Figura 8. Tela inicial de consulta.

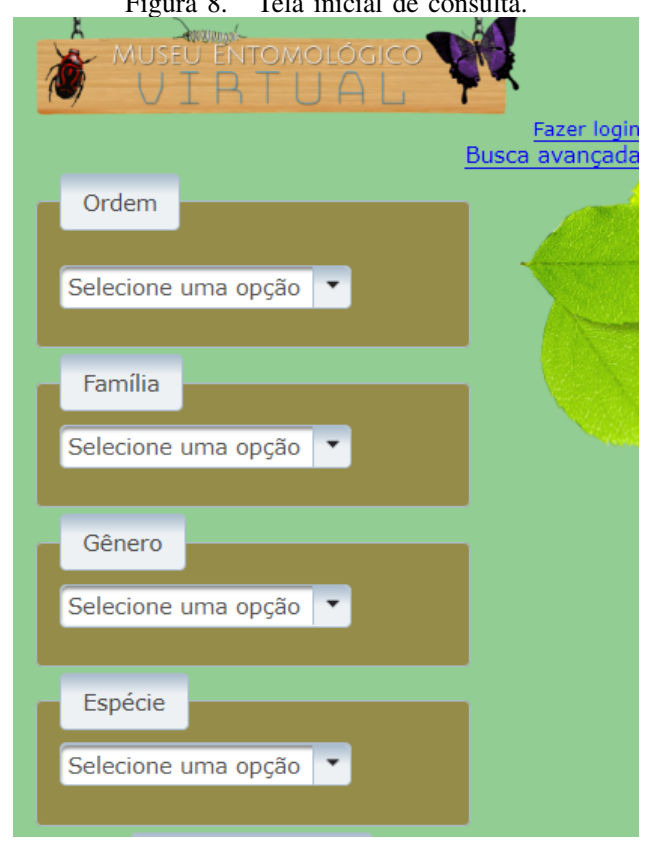

Fonte: os autores.

Figura 9. Espécie visualizada em três ângulos.
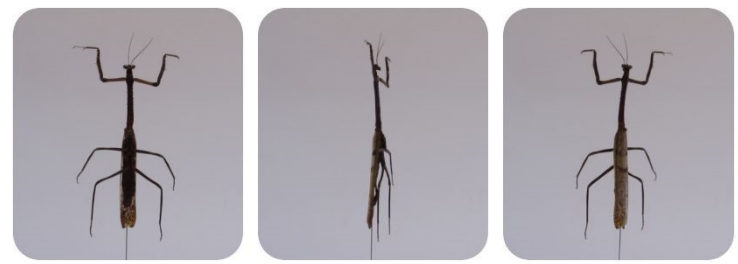

Fonte: os autores.

Estas fotos devem ter sido preparadas previamente, conforme descrito na subseção IV-B.

A pagina de upload é apresentada na Figura 11.

Uma vez realizado o upload as imagens são enviadas para o servidor, como descrito na subseção IV-C, tornando acessível para o público a visualização de 360 graus do inseto cadastrado no sistema.

\section{Resultados}

Neste trabalho um museu entomológico virtual foi desenvolvido. Este produto de software apresenta características diferentes de alguns museus existentes. Por isto, nesta seção são apresentadas algumas comparações entre o EntoMuseu e coleções físicas, bem como entre este e museus existentes. Em seguida é mostrada uma avaliação por usuários.

\section{A. Comparação com coleções físicas}

A forma convencional de se ter coleções de insetos é manter exemplares reais das espécies conservados por meio de produtos químicos. Nos museus entomológicos, segundo [11], para manter uma espécie conservada por mais tempo
Figura 10. Cadastro de Inseto

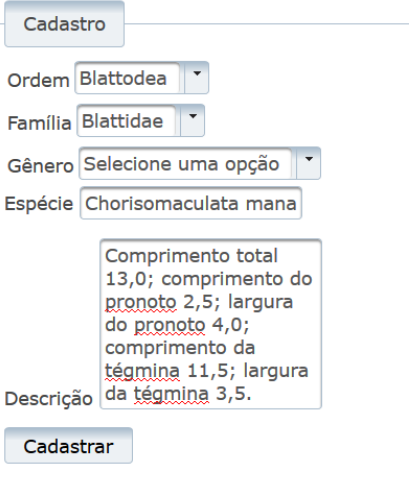

Fonte: os autores.

Figura 11. Upload das Imagens

\section{Horizontal}

Obs: Selecione as 15 imagens de uma vez.

Caso não tenha, deixar em branco.

+ Choose , Upload a Cancel

Vertical

Obs: Selecione as 15 imagens de uma vez.

Caso não tenha, deixar em branco.

Choose Upload a Cancel

precisa-se de alguns cuidados periódicos, como por exemplo nas caixas dos insetos deve existir uma quantidade de naftalina para evitar aparição de micro organismos que consomem os insetos. Mesmo com a utilização dessa substância, com o decorrer, do tempo as espécies tendem a se decompor naturalmente, ocasionando em uma perda dos exemplares da coleção de insetos. Já no ambiente virtual os insetos nunca irão entrar em estado de decomposição. Outra vantagem que também destaca o museu virtual é a sua acessibilidade, uma vez que pode ser consultado em qualquer lugar do mundo que tenha conexão com a internet, podendo na maioria dos casos ser mais cômodo.

\section{B. Comparação com museus entomológicos virtuais existen-} tes

Anteriormente neste texto, foram apresentados, na fundamentação teórica, exemplos de alguns museus virtuais existentes e mostradas suas características. Em alguns museus virtuais, são mostradas apenas fotografias de insetos, geralmente tiradas da parte superior, o que limita bastante a observação. Em outros casos, a fotografia mostra um conjunto de espécies de uma determinada família, dificultando 
a observação dos detalhes.

No EntoMuseu, por outro lado, é possível girar o inseto e observá-lo por vários ângulos. Além disso, são disponibilizadas duas opções de visualização: horizontal e vertical, o que enriquece ainda mais a observação.

\section{Avaliação por critérios de museologia}

Morville e Rosenfeld, apud Petrucci [12], comentando arquitetura da informação para ambientes virtuais, dizem estes devem combinar quatro elementos:

- Organização: determina a organização e categorização da informação;

- Navegação: possibilidade de o usuário interagir com a máquina;

- Rotulação: criação de identificação que possibilite a busca posterior; e

- Busca: Possibilidade de buscar em um banco de dados.

No museu entomológico virtual o elemento organização classifica as espécies em três categorias: ordem, família e gênero. Na navegação esta garantida pela interface web na qual é possível selecionar os insetos e o ângulo que se deseja visualizar. Já a rotulação está presente no momento de cadastro das espécies, as quais recebem o nome científico para sua identificação. A busca, em se tratando de um sistema de consulta, pode ser considerada um dos principais elementos do museu, por isso, uma atenção especial foi dada a ela quando do desenvolvimento do ambiente.

Já Deloche apud Jahn [2], quando se considera o uso da imagem de natureza digital, diz que o museu deve cumprir pelo menos três de suas funções mais importantes:

- Preservação;

- Exposição; e

- Estudo.

Considerando o EntoMuseu, a questão da preservação tem o sentido de manter a espécie original intacta sem riscos de sofrer danos, enquanto se expõe a imagem digitalizada dela. Já a exposição é a disponibilização das imagens das espécies da coleção, tornando acessível a visualização pelos usuários. O estudo está presente na possibilidade de consultar as informações descritas de cada espécie, como o seu tamanho e habitat. Em resumo, o museu virtual desenvolvido pode cumprir as três funções descritas por Deloche.

\section{Avaliação pelo público}

Uma vez que o software tem possibilidades educacionais, considerou-se conveniente submetê-lo à análise por eventuais usuários. Trata-se de uma análise qualitativa, uma vez que buscou-se opiniões subjetivas dos sujeitos participantes [13]. Foi conduzida no formato de pesquisa de opinião, que de acordo com Pfleeger [24], registra como pessoas reagem a uma ferramenta. Foi elaborado um questionário e aplicado com alunos que cursaram a disciplina Entomologia Agrícola do curso de Agronomia, com grau de conhecimento médio nesta área. Vale ressaltar que esta foi uma avaliação inicial, a fim de verificar a viabilidade do produto. Utilizouse a escala de Likert, a qual estabelece cinco possibilidades de respostas:

1) - Discordo plenamente

2) - Discordo

3) - Neutro

4) - Concordo

5) - Concordo plenamente

Resumidamente, a opinião dos usuários foi que:

1) O sistema não é complexo de usar.

2) O usuário não precisaria de ajuda de uma pessoa com conhecimentos técnicos para utilizar o sistema.

3) As funções do sistema estão bem integradas.

4) As pessoas aprenderão usar o sistema rapidamente.

5) O programa não é atrapalhado para usar.

6) Os usuários sentiram-se confiantes em usar o sistema.

7) Não é necessário aprender várias coisas novas antes de usar o sistema.

8) Para o estudo de entomologia, um museu virtual é importante.

9) Com a visualização das espécies em 360 graus é possível observar melhor os detalhes do que em uma fotografia $2 \mathrm{D}$.

10) A visualização em 360 graus é tão rica quanto a observação real.

Além das questões fechadas, foi deixado um espaço para que os participantes pudessem escrever opcionalmente seus comentários e sugestões referentes ao sistema.

Os comentários foram que o sistema deveria possibilitar a busca das espécies utilizando o nome popular e não somente por meio do nome científico. Também sugeriram que a visualização da espécie, tanto na vertical como na horizontal, poderia permitir realizar uma aproximação (zoom) das imagens, para observar ainda mais os detalhes dos insetos.

Em resumo, a avaliação do museu desenvolvido foi positiva, com base nas opiniões dos usuários, em relação aos critérios de museologia bem como em comparação com aos museus entomológicos virtuais existentes.

\section{CONCLUSÃO}

Neste trabalho foi relatado o desenvolvimento de um museu entomológico virtual de baixo custo. A forma de disponibilização das imagens permite que o usuário as gire em 360 graus, podendo observar os detalhes de cada espécie. Esta observação é importante no contexto educacional, uma vez que o estudo dos insetos é importante em diversas áreas, como Biologia e Agronomia. O fato de estar disponível na web torna mais acessível e, embora sem a mesma riqueza de detalhes que teria uma observação do inseto real, permite a observação de qualquer lugar e em qualquer hora, o que não é possível em coleções físicas presentes em museus ou laboratórios de pesquisa. É importante citar que o método 
utilizado é inovador, uma vez que utiliza materiais de baixo custo e softwares livres para tratamento das imagens.

Embora o produto desenvolvido encontre-se na fase de protótipo, pode ser avaliado positivamente, tanto por critérios presentes na literatura quanto pela opinião de usuários (estudantes de entomologia). Considerando-se que, de maneira geral, a tendência é migrar as bases de conhecimento para a web, a criação de museus virtuais, incluindo os museus entomológicos, é extremamente importante. Por isso, o desenvolvimento de métodos simples e de baixo custo como o apresentado neste trabalho, mostram-se fundamentais.

No que se refere às ferramentas utilizadas, optou-se por empregar apenas software livre no desenvolvimento. Pode-se concluir que foi possível executar todas as fases do projeto com esta categoria de software. Inicialmente, o programa FFmpeg foi utilizado, para transformar um filme em diversas imagens jpeg. Estas imagens posteriormente podem ser exibidas como um objeto 3D, por meio do jQuery Interactive 3D. Em se tratando de ambiente web, foram utilizados o servidor Apache Tomcat como container, o gerenciador de banco de dados PostgreSQL para o gerenciamento de usuários e JavaServer Faces/Primefaces para construção das páginas.

Pode-se afirmar que a contribuição deste trabalho foi demonstrar que a utilização de software livre para construção de museus virtuais é tecnicamente viável, além de reduzir os custos de desenvolvimento. Como trabalho futuro, uma possibilidade é aplicar técnicas de user experience (UX) ao projeto.

\section{AgRADECIMENTOS}

Os autores agradecem à Fundação Araucária pelo apoio financeiro ao projeto por meio do PIBEX - Programa Institucional de Bolsas de Extensão Universitária e do Programa Universidade Sem Fronteiras.

\section{REFERÊNCIAS}

[1] T. W. S. P. Lima, C. E. Ribeiro, J. R. Merlin, G. C. Guerino,B. A. G. Zancan, E. M. Sgarbi, T. X. Godoi, D. G. F. Trindade. Framework conceitual de apoio ao design de museus virtuais com foco em interfaces naturais. In: XVII Simpósio Brasileiro de Fatores Humanos em Sistemas Computacionais, 2018, Belem - PA. Anais Estendidos do XVII Simpósio Brasileiro de Fatores Humanos em Sistemas Computacionais (IHC), 2018.

[2] A. R. M. Jahn. O museu que nunca fecha: A exposição virtual digital como um programa de ação educativa. Tese (Doutorado) - Escola de Comunicação e Artes - Universidade de São Paulo, 2016.

[3] F. M. Lara. Princípios de entomologia. 3. ed. São Paulo: Ícone, 1992.

[4] D. Geary, C. Horstmann. Core JavaServer Faces. Santa Clara: Addison Wesley, 2004.
[5] ICOM. Museum Definition. 2019. Disponível em: https://icom.museum/en/activities/standardsguidelines/museum-definition/. [Online; acessado 01-Julho2019].

[6] M. R. Petrucci. Ambientes Virtuais: Educação e cultura na construção do museu virtual José Américo de Almeira. Dissertação (Dissertação de Mestrado) — Universidade Federal da Paraíba, 2010.

[7] P. Klimpel. Where do museums stand in the digital age? private companies, heritage institutions and the civil society. In: NEMO 21st Annual Conference Documentation. [S.1.: s.n.], 2013.

[8] J. Andrews, W. Scheibenz. The kress study collection virtual museum project, a new medium for old masters. Art Documentation, v. 17, n. 1, p. 19-27, 1998.

[9] G. C. Guerino, M. A. Simon, B. S. Faical, J. R. Merlin. Desenvolvimento de museu entomológico virtual de baixo custo. In: Anais do III Encontro de Integração UENP. Jacarezinho, 2017.

[10] NETWORK, H. Software Installation and Pre-processing. 2016. https: //hydrologicnetwork.com/lessons/softwareinstallation-and-pre-processing. [Online; acessado 05-março2019].

[11] M. Obara, M. V. Wanderley, R. A. Silva. Procedimentos de captura, montagem, conservação e envio. Curitiba: SciELO Books, 2014.

[12] M. R. Petrucci. Ambientes Virtuais: Educação e cultura na construção do museu virtual José Américo de Almeira. Dissertação (Dissertação de Mestrado) - Universidade Federal da Paraíba, 2010.

[13] J. T. F. Suzuki, M. C. B. Steinle, O. Battini. TCC Elaboração e Redação. Londrina: Redacional Livraria, 2009.

[14] F. Teixeira. O que é o SUS (System Usability Scale) e como usá-lo em seu site. 2015. [Online; acessado 05-março-2019]. Disponível em: [http://brasil.uxdesign.com].

[15] O. Varaksin, M. Caliskan. PrimeFaces Cookbook. Birmingham UK: Packt Publishing, 2013.

[16] FFmpeg. In: WIKIPÉDIA, a enciclopédia livre. Flórida: Wikimedia Foundation, 2018. Disponível em: [https://pt.wikipedia.org/w/index.php?title=FFmpeg\&oldid $=53842081]$. Acesso em: 17 dez. 2018 .

[17] Javascript. In: WIKIPÉDIA, a enciclopédia livre. Flórida: Wikimedia Foundation, 2019. Disponível em: ¡https://pt.wikipedia.org/w/index.php?title=JavaScript\&oldid $=55680462 i$. Acesso em: 8 jul. 2019 .

[18] Pete R. jQuery Interactive 3D. Disponível em: [https://github.com/peachananr/interactive_3d]. Acesso em: 8 jul. 2019.

[19] D. F. Schlosser; A. C. Frasson; J. R. H. Cantorani. Softwares Livres para análise de dados qualitativos. Revista Brasileira de Ensino de Ciência e Tecnologia. Ponta Grossa, v. 12, n.1, p. 539-550. 2019. 
[20] J. Krause. Introducing Web Development. Berlin, Germany: Apress, 2018.

[21] ESALQ. Museu de Entomologia ESALQ-USP. Disponível em: http://www.me.esalq.usp.br/. Acesso em: 13 de setembro de 2019.

[22] UALBERTA. Entomology Collection. Disponível em: http://www.entomology.ualberta.ca/. Acesso em: 13 de setembro de 2019.

[23] UNIVERSIDAD NACIONAL DE COLOMBIA. Museo Entomólogico Francisco Luis Gallego. Disponível em: http://ciencias.medellin.unal.edu.co/museos/entomologico/MuseoVirtual/. Acesso em: 13 de setembro de 2019.

[24] S. L. Pfleeger. Engenharia de Software. 2. ed. São Paulo: Prentice Hall, 2004. 